\title{
A comparison between gastroesophagheal ultrasonography vs. barium swallow in determining the pattern of gastroesophageal reflux in a pediatric population
}

\author{
Alireza Khatami ${ }^{1}$, Mohammad Mahdi Allameh ${ }^{1}$, Makhtoom Shahnazi ${ }^{2}$, Azadeh Kiumarsi ${ }^{3}$, \\ Ali Tajik ${ }^{4}$
}

${ }^{1}$ Department of Radiology, Mofid Children's Hospital, Shahid Beheshti University of Medical Sciences, ${ }^{2}$ Department of Radiology, Loghman Hospital, Shahid Beheshti University of Medical Sciences, ${ }^{3}$ Department of Pediatry, St Ali Asghar Children's Hospital, Iran University of Medical Sciences, ${ }^{4}$ Department of Community Medicine, Tehran University of Medical Sciences, Iran.

\begin{abstract}
Background: Gastroesophageal reflux disease (GERD) is one of the most common gastrointestinal pathology in infants and young children. Ultrasonography (US) has been considered to be a reliable diagnostic tool for GERD but the severity of GERD and the clinical implications based on imaging findings has not been evaluated. Aims: To compare the diagnostic value of lower esophageal US with that of barium swallow in demonstrating the severity of GERD. Materials and methods: Fifty one pediatric patients, age between 1 month to 12 years, 34 male and 17 female with clinical suspicion of GERD were included. The patients were initially submitted to barium swallow (BS) and subsequently to transabdominal US. During BS, the number of gastroesophageal reflux episodes was documented in a 5-minute period. Transabdominal US documented the number and duration of reflux episodes during a 5-minute period, the angle of His, mucosal thickness, and intraabdominal esophageal length (IAEL). Results: Duration and number of reflux episodes in US were significantly higher in patients that had severe gastroesophageal refluxes at BS. At US the cutoff point of 9.5 seconds (sensitivity $80 \%$, specificity $60 \%$ ) for reflux duration and more than 2 episodes in 5 minute ultrasound study (sensitivity $75 \%$, specificity 58\%) were defined to correlate with severe gastroesophageal reflux at BS.The angle of His, the esophageal wall mucosal thickness, and the IAEL did not correlate with the severity of GERD detected in BS. Conclusion: US can predict the severity of GERD. Therefore, except in the case of specific patients in whom mechanical causes are suspected to be responsible for GERD, BS can be replaced by US.
\end{abstract}

Keywords: gastroesophageal reflux, ultrasonography, barium swallow.

\section{Introduction}

Gastroesophageal reflux disease (GERD) is the most common esophageal disorder in infant and children causing intermittent regurgitation or vomiting [1]. Although it is a physiological event in most adults and children, it becomes pathological when the intensity and/or frequency are increased [2]. In this context, early diagnosis and treat-

Received 16.08.2014 Accepted 06.12.2014

Med Ultrason

2015, Vol. 17, No 1, 22-27

Corresponding author: Azadeh Kiumarsi

20 Danesh Ave, South Falamk Street,

Shahrake gharb, Tehran, Iran

Phone: 00982188579492

Fax: 00982188376499

E-mail: raha1221@yahoo.com ment is important to prevent potentially serious complications, such as severe esophagitis, esophageal stenosis, and aspiration syndrome [3]. Nevertheless, one of the difficulties of GERD management in children is the process of its diagnosis [4]. Upper gastrointestinal contrast series, esophageal $\mathrm{pH}$ monitoring, nuclear scintigraphy, and esophageal manometry are the most commonly used diagnostic techniques for the diagnosis of GERD in children [5].

Although the monitoring of $\mathrm{pH}$, manomety, and gastroesophageal junction scintigraphy are sensitive and with high diagnostic value techniques, the morphological aspects cannot be assessed by these methods. Additionally, the methods are invasive and are not always available $[6,7]$.

Upper gastrointestinal series of barium swallow (BS) has been the preferred method for visualizing clinically 
suspected GERD [2]. Despite several advantages as having a key role in the detection of structural anomalies (e.g. hiatus hernia, malrotation) [8] along with the valuable experiences that practitioners have acquired through the years since the 1980s, ultrasonography (US) has been used as an alternative to BS in the diagnosis of GERD [9]. Esophageal US has been described as a noninvasive, readily available, repeatable, cheap, and fast technique that could be commonly used in the diagnosis and follow-up of young children with GERD [10-15]. Comparative studies of transabdominal US and BS demonstrated that US presents a higher sensitivity in the diagnosis of GERD [16,17]. Additionally, US proved to be more effective in the evaluation of the intraabdominal esophagus with a reduction of the exposure to ionizing radiation for these patients $[18,19]$. However, the determination of GERD degree which can be performed specifically with $\mathrm{BS}$, has not appeared to be reachable for US in many studies $[20,21]$.

The aim of this study was to investigate the correlation between the US measurement of the angle of His, mucosal thickness of the esophagus, the length of intraabdominal esophagus, and the frequency and duration of reflux episodes with the severity of reflux episodes detected on BS.

\section{Material and methods}

Informed consent was obtained for every patient from their parents/guardians and the research protocol was approved by our Institute's Ethics Committee.

This cross sectional study was performed on pediatric patients ( 1 month to 12 years of age) referred to Mofid Children's Hospital in order to undergo BS and meal with clinical suspicion of GERD. Patients with radiographic findings or history of disease causing anatomical or functional alteration of the esophagus and/or stomach (i.e. fistulas, surgical interventions, or hiatal hernia), and those with medical conditions predisposing GERD (cerebral palsy, metabolic diseases, etc) were excluded from the study.

A total number of 51 children including 34 males and 17 females were studied.

The clinical history of 50 patients and their weights were recorded at the time of admission. In one child the clinical history and weight was not properly recorded.

All patients underwent barium study by drinking 50 $250 \mathrm{ml}$ dilute barium suspension $25 \% \mathrm{w} / \mathrm{w}$ according to the patient' age. The patients were observed during a 5 minute period using intermittent fluoroscopic radiography of the gastroesophageal junction. Patients' position during this observation was supine and/or right side down

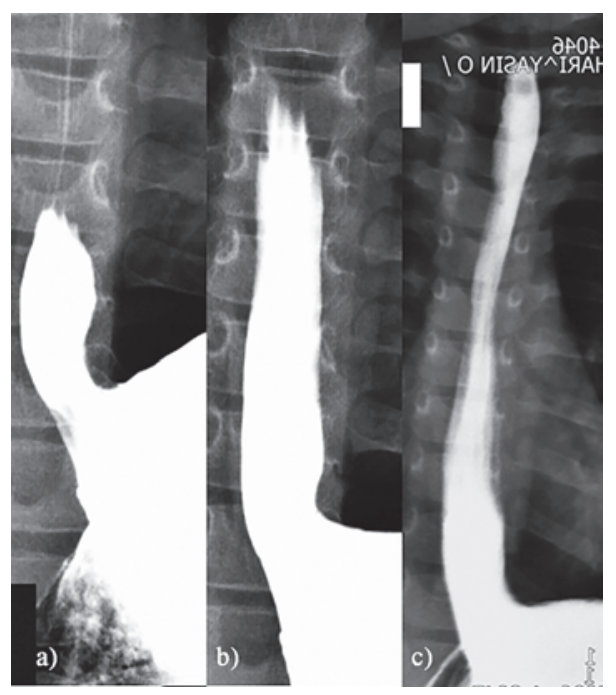

Fig 1. Barium study. Grading of the reflux according to height of the column of barium refluxed to the esophagus: a) mild (ascending to distal one third), b) moderate (middle one third), and c) severe (upper one third)

decubitus. The total number of gastroesophageal reflux episodes and the amplitude of the reflux were recorded by staff radiologist with 6 years experience in pediatric radiology. The reflux episodes were graded based on the height to which it ascended into esophagus in mild (ascending to distal one third), moderate (middle one third), and severe (upper one third of esophagus) (fig 1).

Subsequently patients underwent transabdominal esophageal US. The children were supplementary fed by their parents with additional fluid or milk in order to fill the stomach. The mean time interval between BS and US was 20 minutes and the parents were asked to make sure that the small kids had burped before the procedure. US was performed using curved $3.5 \mathrm{MHz}$ and/ or linear 7.5 MHz transducers, Medison Accuvix XQ machine, South Korea. The patient position was supine and/or right side down decubitus. Visualization of the abdominal esophagus was achieved in longitudinal section by placing the transducer in the midline line, below the xiphisternum, with cephalic angulation, tilted to the right, and slightly rotated counter-clockwise relative to the sagittal plane. Liver was maintained as an acoustic window (fig 2a).

The intraabdominal esophagus length (IAEL), mucosal thickness, and the angle of His were measured and documented. IAEL was measured from the point in which it penetrated the diaphragm to the base of the triangular pad of gastric folds (considered the point of entrance of the esophagus into the stomach) at the anterior surface of the fundus of the stomach (fig $2 b$ ). 


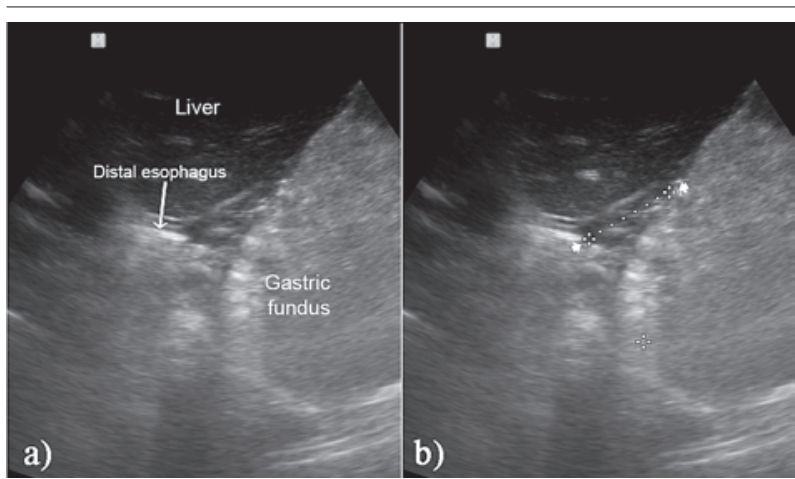

Fig 2. Transabdominal ultrasound: a) echogenic flow in the distal esophagus (arrow); b) esophageal length measurement.

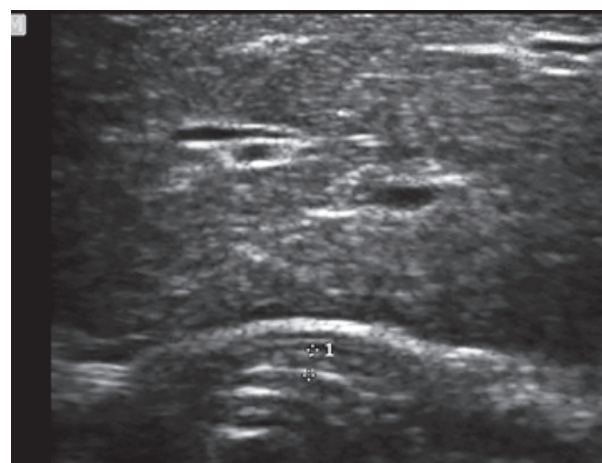

Fig 3. Measurement of mucosal and submucosal layers (between calipers).

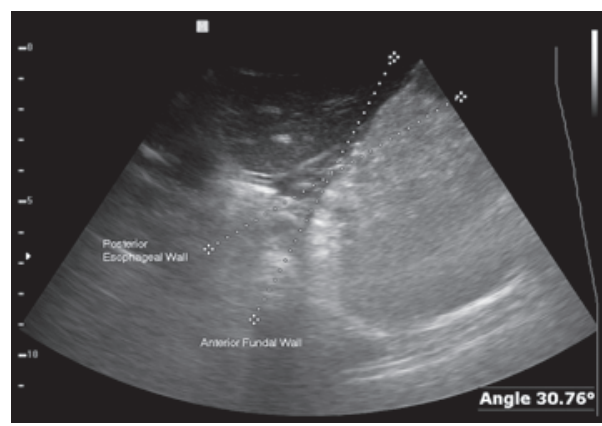

Fig 4. His angle measurement.

Mucosal thickness was measured by placing the clipper between the inner echogenic line (inner face of the echogenic mucosal layer) and the outer hypoechoic line of the muscularis propria. This thickness included echogenic superficial mucosa, hypoechoic deep mucosa, and echogenic submucosa (fig 3).

The angle of His was measured between the posterior esophageal wall and the anterior fundal wall (fig 4).

The number and the duration of the reflux episodes (backward movement of ingested fluid up into esophagus) were documented during a 5-minute period examination. The fluid was visualized as an hypoechoic flow through distal esophagus, as a stream of fluid with debris due to mixing water, milk, and barium, or as an echogenic fluid (a mixed of fluid with hyperechoic bubbles of ingested air) .

\section{Statistical analysis}

The data were analyzed with Chi square, Fisher's exact test, Independent t-Test, ROC Curve and ANOVA using SPSS software version 13. The level of significance was set at $\mathrm{p}$ value of less than 0.05 .

\section{Results}

A total of 51 cases of pediatric patients, with the mean age of 29.7 months (age range 1 to 144 months), mean weight of $11.14 \mathrm{~kg}$, and a female to male ratio of $1: 2$ were enrolled in the study. The correlation of age, weight, and sex with the severity of reflux in BS is illustrated in table I. The signs and symptoms at presentation and their correlation with the severity of reflux in BS are detailed in table II.

Regarding to the US findings, the duration and the frequency of reflux episodes significantly correlated with the severity of refluxes graded by BS $(\mathrm{p}=0.037$ and $\mathrm{p}=0.007$ respectively, table III). We appreciated that the high grade gastroesophageal reflux (visualized by BS) is characterized in 5-minutes US study by a cutoff of 9.5 seconds for reflux duration (sensitivity $=80 \%$, specificity $=60 \%$ ) and more than 2 episodes of reflux (sensitivity $=75 \%$, specificity $=58 \%$ ). To and fro movements of refluxed material detected by US and their occurrence was also associated with sever reflux in BS $(\mathrm{p}=0.014)$.

The angle of His, the esophageal wall mucosal thickness, and the IAEL did not correlate with the severity of GERD detected in barium study.

\section{Discussions}

Symptoms and signs associated with GERD are nonspecific, hence a clinical diagnosis of GERD cannot be used in infants and children who cannot reliably express the quality and quantity of their symptoms [22]. As a result, diagnostic tests are needed to document the presence of GERD, to detect the complications, to establish a causal relationship between severity of GERD and symptoms, to evaluate the therapy, and to exclude other conditions [23].

Several methods are available for the evaluation and diagnosis of GERD in children [12,24,25].

The gold standard for diagnosis is 24-hour ambulatory $\mathrm{pH}$-metry and manometry but these modalities are not available in many clinics or medical centers and $\mathrm{pH}$ probes are expensive as well. The BS, the oldest diagnostic method used in this category, can evaluate the mu- 
Table I. The correlation of age, weight, and sex with the pattern of reflux in BS.

\begin{tabular}{|c|c|c|c|c|c|}
\hline Barium study & $\mathrm{N}=\mathbf{5 1}$ & $\begin{array}{l}\text { Age } \\
\text { (month) }\end{array}$ & $\begin{array}{l}\text { Weight } \\
\text { (Kg) }\end{array}$ & Sex & \\
\hline Negative & $8(15.7 \%)$ & 50.75 & 15.92 & $\begin{array}{l}\mathrm{M} \\
\mathrm{F}\end{array}$ & $\begin{array}{l}7 \\
1\end{array}$ \\
\hline Mild reflux & $3(5.9 \%)$ & 31.0 & 11.85 & $\begin{array}{l}\mathrm{M} \\
\mathrm{F}\end{array}$ & $\begin{array}{l}2 \\
1\end{array}$ \\
\hline Moderate reflux & $5(9.8 \%)$ & 22.4 & 6.1 & $\begin{array}{l}\mathrm{M} \\
\mathrm{F}\end{array}$ & $\begin{array}{l}5 \\
0\end{array}$ \\
\hline Severe reflux & $35(68.65 \%)$ & 14.69 & 10.7 & $\begin{array}{l}M \\
F\end{array}$ & $\begin{array}{l}20 \\
15\end{array}$ \\
\hline
\end{tabular}

$\mathrm{N}$ - number of patients, $\mathrm{M}$ - male, $\mathrm{F}$ - female

cosal alterations and the anatomical abnormalities [22]; additionally, it can provide a good representation for classifying the severity of reflux [26,27].

However, the effective dose of a barium meal study is $2.6 \mathrm{mSv}$, i.e. the radiation dose equals the dose of 130 chest radiographs [28]; as a result, in order to reduce the exposure to ionizing radiation in pediatric patients, other diagnostic methods are being investigated to replace BS in determining the severity of GERD.

In the study conducted by Macharia et al, no association was found between the height of the esophageal reflux determined by BS, as an indicator of reflux severity, and the number of reflux episodes in the $\mathrm{pH} /$ impedance tests [27]. Neither Al-Khawari et al found correlations between the severity of reflux in BS and the results of 24-h esophageal $\mathrm{pH}$ monitoring [26].

In our study we compared the results of transabdominal US and BS in view of the severity of reflux. We found that the duration of reflux episodes in US were signifi- cantly correlated with the severity of reflux detected in BS and we established a cutoff point of 9.5 seconds for severe reflux. The frequency of reflux episodes in US was also related with the reflux severity: more than 2 episodes of reflux in US had significance of severe reflux in BS. Sakate et al did not find a correlation between the frequency of reflux episodes in US and the frequency of episodes in BS [19] but they did not compare the frequency of episodes in US with the height of the reflux column in BS.

Intraabdominal esophagus is one of the main elements of the gastroesophageal junction, and its length constitutes an important diagnostic indicator in children with GERD. In spite of its difficulty, the measurement of the abdominal esophagus length can be achieved by US, and a shortening of as little as $2 \mathrm{~mm}$ can be detected $[29,30]$.

Nemati et al found that the mean length of the subdiaphragmatic esophagus in the patients with GERD was significantly shorter than controls; moreover, children with severe reflux had a shorter esophagus [31]. Other studies confirmed their findings [12, 32, 33]. In our study, although the IAEL did not significantly correlate with the severity of reflux in BS, we found that the IAEL was shorter in normal comparing with mild and moderate BS.

Changchien et al [34] measured the gastroesophageal junction' wall thicknesses in adults and found the wall to be thicker in the reflux esophagitis group compared with normal subjects. They related this thickening to the severe inflammation of the reflux esophagitis. In a study of Mine et al [35], the submucosal healing during lansoprazole treatment for GERD disease was evaluated by US.

Table II. Presenting symptoms and their correlation with the pattern of reflux in BS.

\begin{tabular}{lllll}
\hline Presenting symptoms & \multicolumn{3}{l}{ Barium study $(\mathbf{n}=\mathbf{5 0}$ patients) } & \\
& Negative & Mild & Moderate & Severe \\
\hline Vomiting & $4(14.3 \%)$ & $1(3.6 \%)$ & $3(10.7 \%)$ & $20(71.4 \%)$ \\
Retching & 0 & 0 & 0 & $1(100 \%)$ \\
Cough/Wheezing & $2(20 \%)$ & 0 & $1(10 \%)$ & $7(70 \%)$ \\
Dysphagia & $1(50 \%)$ & 0 & $1(50 \%)$ & 0 \\
Pain & $1(33.3 \%)$ & $1(33.3 \%)$ & 0 & $1(33.3 \%)$ \\
Agitation & 0 & 0 & 0 & $1(100 \%)$ \\
Pneumonia & 0 & 0 & 0 & $2(100 \%)$ \\
Constipation & 0 & 0 & 0 & $1(100 \%)$ \\
Others & 0 & 0 & 0 & $2(100 \%)$ \\
\hline
\end{tabular}

Table III. The ultrasonographic measurement and their correlation with the pattern of reflux in barium swallow.

\begin{tabular}{llllll}
\hline Barium swallow & IEUS & & & & \\
& Duration (sec) & Frequency & IAEL $(\mathbf{m m})$ & Mucosal thickness $(\mathbf{m m})$ & Angle of His (degree) \\
\hline Negative & 5.4 & 0.63 & 19.53 & 2.25 & 48.42 \\
Mild & 13.67 & 2 & 25.66 & 1.63 & 50 \\
Moderate & 6.2 & 2.2 & 22.2 & 2.3 & 43 \\
Severe & 13.81 & 2.49 & 17.72 & 2.47 & 51.7 \\
\hline
\end{tabular}

IAUS- intraabdominal esophagus ultrasonography; IAEL- intraabdominal esophagus length 
The authors found that the wall thickness had decreased significantly in the gastroesophageal junction region. In the current literature we found no study that measured the mucosal thickness of the esophageal wall in gastroesophageal junction in children using US. Even though not correlated significantly with the severity of reflux in BS, our results could be used in the future studies.

In a study undertaken by Westra et al [33], the gastroesophageal junctions of 30 young children proven to have GERD were examined with US. The authors described a rounded gastroesophageal angle associated with significant GERD. In accordance with the study by Halkiewicz et al [32] we also found an obtuse angle of His in children with GERD, but its degree was not significantly correlated with the severity of reflux in barium study.

Our study has some limitations. Firstly, the gold standard for evaluation of GERD and for correlation with clinical findings is considered to be $\mathrm{pH}$ monitoring, which was not used in our study. Secondly, the small number of cases of the study did not permit us to make comparisons between different groups of ages. Thirdly, we did not follow up the patients and so the comparison between the severity of the GERD and evolution could not be done.

In conclusion, although GERD is a clinical diagnosis there is not a noninvasive test available to confirm the diagnosis in doubtful cases. We emphasize that, TAEUS as a noninvasive and simple diagnostic method can be used with high diagnostic value in determining which pattern of reflux may need more clinical attention in patients with suspicion of GERD.

\section{Refrences:}

1. Di Mario M, Bergami G, Fariello G, Vecchioli Scaldazza A. Diagnosis of gastroesophageal reflux in childhood. Comparison of ultrasonography and barium swallow. Radiol Med 1995; 89:76-81.

2. Matrunola M, Grandin A, Mazza ML, Panetta A, Giardini V, Corrado G. Role of radiography and ultrasonography in the diagnosis of the pediatric gastro-esophageal reflux disease. Eur Rev Med Pharmacol Sci 2003; 7: 147-149.

3. Da Dalt L, Mazzoleni S, Montini G, Donzelli F, Zacchello F. Diagnostic accuracy of $\mathrm{pH}$ monitoring in gastro-oesophageal reflux. Arch Dis Child 1989; 64:1421-1426.

4. Fallahi G, Saneian H, Mahdizadeh M, Farahmand F. Children, GERD and ultrasound. Acta Medica Iranica. 2007; 45: 355-360.

5. Koivusalo AI, Pakarinen MP, Wikström A, Rintala RJ. Assessment and treatment of gastroesophageal reflux in healthy infants with apneic episodes: a retrospective analysis of 87 consecutive patients. Clin Pediatr 2011; 50: 1096-1102.

6. Gomes H, Menanteau B. Gastroesophageal reflux: comparative study between sonography and $\mathrm{pH}$ monitoring. Pediatr Radiol 1991; 21: 168-174.
7. Karabulut B, Bostanci I, Kacar M, Karaca G, Kosar P. Transcutaneous cervical and transabdominal ultrasonography as a diagnostic tool in gastroesophageal reflux in childhood. ORL J Otorhinolaryngol Relat Spec 2010; 72: 300-304

8. Arasu TS, Wyllie R, Fitzgerald JF, et al. Gastroesophageal reflux in infants and children comparative accuracy of diagnostic methods. J Pediatr 1980; 96: 798-803.

9. Naik DR, Bolia A, Moore DJ. Comparison of barium swallow and ultrasound in diagnosis of gastrooesophageal reflux in children. Br Med J (Clin Res Ed) 1985; 290: 19431945.

10. Wynchank S, Mann MD, Fisher R, Dwyer E. Ultrasound as a screening study for gastro-oesophageal reflux in children. Ann Trop Paediatr 1997; 17: 343-348.

11. Barbolini G, Muratori G, Bertolani MF, et al. Contribution of echography in the diagnosis of gastroesophageal reflux in children. Pediatr Med Chir 1992; 14: 619-622.

12. Koumanidou C, Vakaki M, Pitsoulakis G, Anagnostara A, Mirilas P. Sonographic measurement of the abdominal esophagus length in infancy: a diagnostic tool for gastroesophageal reflux. AJR Am J Roentgenol 2004; 183: 801807.

13. Riccabona M, Maurer U, Lackner H, Uray E, Ring E. The role of sonography in the evaluation of gastro-oesophageal reflux: correlation to pH-metry. Eur J Pediatr 1992; 151: $655-657$

14. Milocco C, Salvatore CM, Torre G, Guastalla P, Ventura A. Sonography versus continuous 24 hours oesophageal $\mathrm{pH}$-monitoring in the diagnosis of infant gastroesophageal reflux. Pediatr Med Chir 1997; 19: 245-246.

15. Kacar S, Uysal S, Kuran S, et al. Transcutaneous cervical esophagus ultrasound in adults: relation with ambulatory 24-hour pH-monitoring and esophageal manometry. World J Gastroenterol 2007; 13: 5245-5252.

16. Swischuk LE. Alimentary tract. In: Swischuk LE (ed). Imaging of the newborn, infant and young child. 3rd ed. Baltimore, Williams \& Wilkins 1989: 353-369.

17. Schindlbeck NE, Heinrich C, König A, Dendorfer A, Pace F, Müller-Lissner SA. Optimal thresholds, sensitivity, and specificity of long-term $\mathrm{pH}$-metry for the detection of gastroesophageal reflux disease. Gastroenterology 1987; 93: 85-90.

18. Milward CMMO. A ultrassonografia como método diagnóstico do refluxo gastroesofágico no paciente pediátrico. Radiol Bras. 2004; 37: 230.

19. Sakate M, Teixeira AS, Yamashita S, et al. Um novo método de avaliação do "tempo esofágico" com ultra-sonografia por abordagem externa. Radiol Bras 2008; 41: 309-312.

20. Lynch CS, Chammas MC, Mansur LL, et al. Biomecânica ultra-sonográfica da deglutição: estudo preliminar. Radiol Bras 2008; 41: 241-244.

21. Spadotto AA, Gatto AR, Cola PC, et al. Software para análise quantitativa da deglutição. Radiol Bras 2008; 41: 25-28.

22. Savino A, Cecamore C, Matronola M, et al. US in the diagnosis of gastroesophageal reflux in children. Pediatr Radiol 2012; 42: 515-524. 
23. Vandenplas Y, Rudolph CD, Di Lorenzo C, et al. Pediatric gastroesophageal reflux clinical practice guidelines: joint recommendations of the North American Society for Pediatric Gastroenterology, Hepatology, and Nutrition (NASPGHAN) and the European Society for Pediatric Gastroenterology, Hepatology, and Nutrition (ESPGHAN). () J Pediatr Gastroenterol Nutr 2009; 49: 498-547.

24. Ashorn M, Ruuska T, Karikoski R, Laippala P. The natural course of gastroesophageal reflux disease in children. Scand J Gastroenterol 2002; 37: 638-641.

25. Salvatore S, Hauser B, Vandenplas Y. The natural course of gastro-oesophageal reflux. Acta Paediatr 2004; 93: 10631069.

26. Al-Khawari HA, Sinan TS, Seymour H. Diagnosis of gastro-oesophageal reflux in children: Comparison between oesophageal $\mathrm{pH}$ and barium examinations. Pediatr Radiol 2002; 32: 765-770.

27. Macharia EW. Comparison of upper gastrointestinal contrast studies and $\mathrm{pH} / \mathrm{impedance}$ tests for the diagnosis of childhood gastro-oesophageal reflux. Pediatr Radiol 2012; 42: 946-951.

28. Hart D, Hillier MC, Wall BF, Shrimpton PC, Bungay D. Doses to patients from medical X-ray examinations in the UK - 1995 review. Report NRPB-R289.
29. Boix-Ochoa J. The physiologic approach to the management of gastric esophageal reflux. J Pediatr Surg 1986; 21 : 1032-1039.

30. Cerri GG. Vísceras ocas. In: Rocha DC, Cerri GG, Prando A, et al. Ultrassonografia abdominal. São Paulo, Sarvier 1988: 169-186.

31. Nemati M, Rafeey M, Roozbehani B, Shakeri Bavil A, Ghabili K. Sonographic measurements of subdiaphragmatic length, diameter, and diameter to length ratio of esophagus in gastroesophageal reflux disease diagnosis in children. Life Science Journal 2013; 10: 985-988.

32. Halkiewicz F, Kasner J, Karczewska K, Rusek- Zychma M. Ultrasound picture of gastroesophageal junction in children with reflux disease. Med Sci Monit 2000; 6: 96-99.

33. Westra SJ, Wolf BH, Staalman CR. Ultrasound diagnosis of gastroesophageal reflux and hiatal hernia in infants and young children. J Clin Ultrasound 1990; 18: 477-485.

34. Changchien CS, Hsu CC. Use of sonography in the evaluation of the gastroesophageal junction. J Clin Ultrasound 1996; 24: 67-72.

35. Mine S, Fujisaki T, Tabata T, et al. Ultrasonographic evaluation of lansoprazole-induced improvement of submucosal injury in patients with gastroesophageal reflux. Am J Gastroenterol 2000; 95: 381-386. 